\title{
Streptococcus cristatus endocarditis presenting as CANCA/PR3-ANCA positive immune complex glomerulonephritis
}

\author{
Andreja Černe Čerček*, \\ David Bele, \\ Nika Kojc, \\ Željka Večerić-Haler
}

University Medical Centre Ljubljana, Ljubljana, Slovenia
A

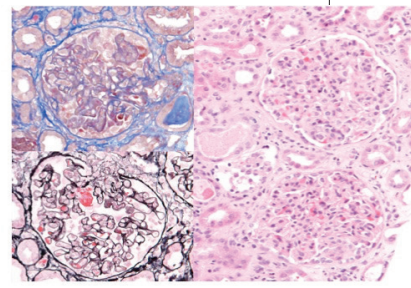

KEYWORDS: streptococcus cristatus endocarditis, immune complex glomerulonephritis.

CITATION: Cardiol Croat. 2017;12(4):128. I https://doi.org/10.15836/ccar2017.128

*ADDRESS FOR CORRESPONDENCE: Andreja Černe Čerček, Univerzitetni klinični center Ljubljana, Zaloška cesta 7, 1000 Ljubljana, Slovenia. / Phone: +386-1-522-50-50 / E-mail: andrejacerne@yahoo.com

ORCID: Andreja Černe Čerček, http://orcid.org/0000-0001-7680-0643 • David Bele, http://orcid.org/0000-0002-6704-8434 Nika Kojc, http://orcid.org/0000-0003-1893-4349• Željka Večerić-Haler, http://orcid.org/0000-0003-3318-9850

IIIIIIIIIIIIIIIIIIIIIIIIIIIIIIIIIIIIIIIIIIIIIIIIIIIIIIIIIIIIIIIIIIIIIIIIIIIIIIIIIIIIIIIIIIIIIIIIIIIIIIIIIIIIIIIIIIIIIII

Introduction: Bacterial and viral infections may trigger different kind of autoantibody production, including PR3 and MPO ANCA. We report a case of subacute bacterial endocarditis in patient with neurofibromatosis type I presenting as c-ANCA/PR3-ANCA glomerulonephritis (GN)

Case report: 57-year-old man with neurofibromatosis type 1 and known mitral valve prolapse, prolonged dry cough, and progressive cachexia was admitted to the hospital due to unexplained renal failure with acute nephritic syndrome, sudden unilateral loss of hearing, vertigo, malaise, new onset hemolytic anemia and thrombocytopenia. Common site of infection, as well as solid malignoma were

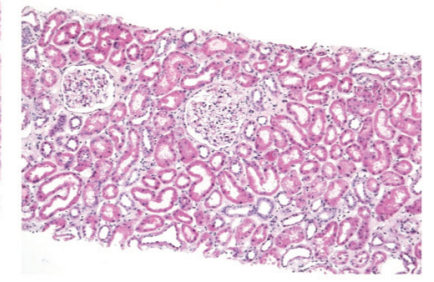
ruled out. Head MRI showed many microscopic hemorrhages. Immunoserology revealed positive c-ANCA/PR3-ANCA and mixed type cryoglobulinemia with low complement fraction C3. The kidney biopsy findings were typical for acute necrotizing crescentic immune complex GN (Figure 1). Due to possible unrecognized infection and coexistence of ANCA-associated vasculitis he was initially treated with intravenous immunoglobulin infusion. Following the kidney biopsy the patient suddenly developed clinical signs of sepsis. Blood cultures revealed Streptococcus cristatus and mitral valve endocarditis was diagnosed (Figure 2). Antibiotic as well as glucocorticoid therapy was started and surgical treatment of mitral valve endocarditis was performed immediately. His serum creatinine level gradually decreased, minimal glomerular erythrocyturia persisted, c-ANCA/PR3-ANCA and cryoglobulins disappeared, C3 level was normal. Second kidney biopsy (Figure 1) was performed to tailor further therapy, and showed the resolution of previously reported findings and steroid therapy was discontinued.

Conclusion: We present the first report of c-ANCA/PR3-ANCA positive immune complex $\mathrm{GN}$ associated with infective endocarditis in neurofibromatosis type I. It is particularly important to be aware of overlapping conditions to make diagnosis in time, as this may have crucial consequences on proper therapy and patient's survival.
FIGURE 1. First (left) and second (right) kidney biopsy. A) Diffuse proliferative glomerulonephritis with focal glomerular necrosis and extracapillary crescent formation (left) and almost normal renal parenchyma with scarce segmental mesangial proliferation (right). B) Immune complex glomerulonephritis in the first biopsy disappeared in the second biopsy
RECEIVED:

March 11, 2017

ACCEPTED:

April 6, 2017

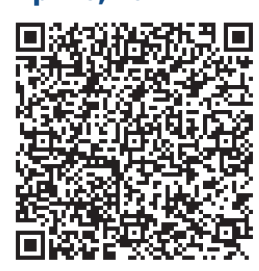

$\square$ Cardiologia Croatica 2017:12(4):128.
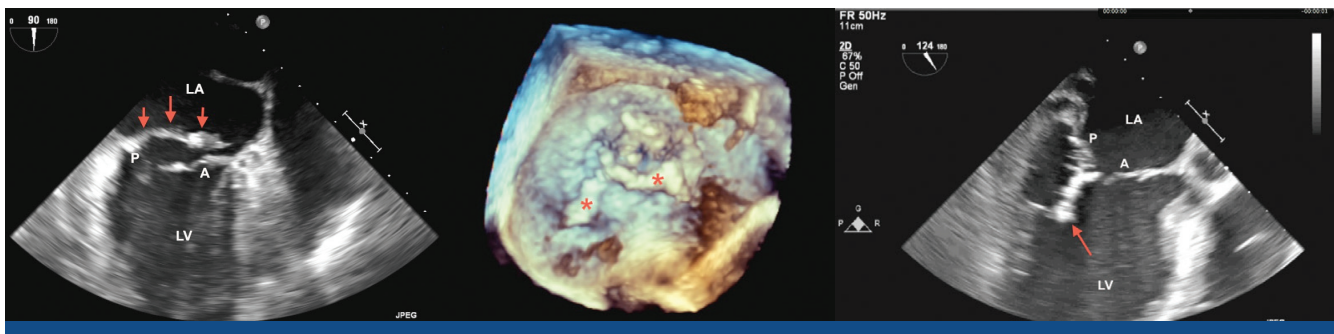

FIGURE 2. Transesophageal ultrasonography shows a large vegetation on the P2 scallop of the posterior mitral leaflet which prolapses into the left ventricle during systole 